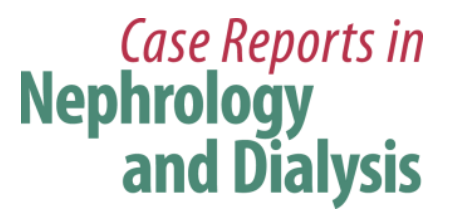

Case Rep Nephrol Dial 2018;8:161-170

DOI: 10.1159/000491629

Published online: August 10, 2018

(C) 2018 The Author(s)

Published by S. Karger AG, Basel

www.karger.com/cnd

This article is licensed under the Creative Commons Attribution-NonCommercial 4.0 International License (CC BY-NC) (http://www.karger.com/Services/OpenAccessLicense). Usage and distribution for commercial purposes requires written permission.

\title{
Case Report: Patient with Hepatitis C, p-ANCA, and Cryoglobulin Antibodies Presenting with Necrotizing Crescentic p-ANCA Glomerulonephritis
}

\author{
Ramy M. Hanna ${ }^{a, b}$ Naomi So ${ }^{b}$ Marian Kaldas $^{b, c}$ Jean Hou ${ }^{d}$ \\ Farid Arman $^{b}$ Michelle Sangalang ${ }^{b}$ e Bishoy Yanny ${ }^{a, b}$ \\ Umut Selamet $^{\mathrm{a}, \mathrm{b}} \quad$ Sammy Saab $^{\mathrm{b}, \mathrm{f}}$ Niloofar Nobakht ${ }^{\mathrm{b}} \quad$ Anjay Rastogi $^{\mathrm{b}}$
}

aUCLA-Southbay Nephrology, Rancho Palos Verdes, CA, USA; bUCLA David Geffen School of Medicine, Westwood, CA, USA; 'UCLA Health-Southbay Rheumatology, Torrance, CA, USA; ${ }^{d}$ Cedars Sinai Medical Center, Renal Pathology, Los Angeles, CA, USA; eUCLA Southbay Family Medicine, Rancho Palos Verdes, CA, USA; fUCLA Ronald Regan Medical Center, Department of Medicine, Division of Hepatology, Westwood, CA, USA

\section{Keywords}

Necrotizing crescentic $p$-ANCA glomerulonephritis - Hepatitis C virus-associated glomerular disease . Perinuclear anti-neutrophil cytoplasmic antibodies · Cryoglobulin antibodies

\section{Abstract}

Hepatitis $\mathrm{C}(\mathrm{HCV})$ infection has a prevalence of 3 million infected individuals in the United States, according to recent Center for Disease Control reports, and can have various renal manifestations. Cryoglobulins, antibodies that precipitate at colder temperatures in vitro, are a relatively common cause of renal disease in HCV infection. The cryoglobulin proteins can form occlusive aggregates in small glomerular capillary lumina or deposit in other areas of the 


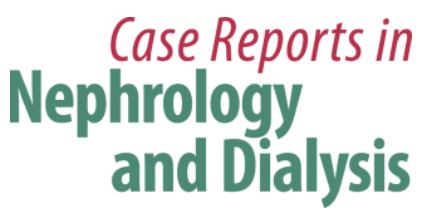

Case Rep Nephrol Dial 2018;8:161-170

DOI: $10.1159 / 000491629$

(C) 2018 The Author(s). Published by S. Karger AG, Base www.karger.com/cnd

Hanna et al.: Case Report: Patient with Hepatitis C, p-ANCA, and Cryoglobulin Antibodies Presenting with Necrotizing Crescentic $p$-ANCA Glomerulonephritis

glomerulus, resulting in hypocomplementemia, proteinuria, hematuria, and renal injury. The typical biopsy pattern is that of membranoproliferative glomerulonephritis (MPGN). There are, however, other HCV-related patterns of glomerular injury. Anti-neutrophil cytoplasmic antibodies (ANCA) are known to exist in HCV-infected patients. In many reported cases, ANCA serologic testing may appear positive due to cross-reactivity of the immune assays; however, the biopsy findings do not support ANCA-associated crescentic glomerulonephritis (GN)/vasculitis as the primary cause of glomerular injury. There are rare reports of microscopic polyangiitis (MPA) p-ANCA vasculitis, in patients with HCV infection. In comparison with the MPGN pattern of cryoglobulinemic glomerular injury, biopsies from these HCV-infected patients with concomitant MPA revealed a crescentic $\mathrm{GN}$, associated with normal serum complement levels. We present a case of HCV-associated glomerular disease with the surprising biopsy finding of necrotizing and crescentic p-ANCA GN, with a background, low-grade mesangial immune complex GN. Thus, p-ANCA disease should also be considered in HCV-infected patients, in addition to the more typical lesions of MPGN or cryoglobulinemic GN.

(C) 2018 The Author(s)

Published by S. Karger AG, Basel

\section{Introduction}

Hepatitis $\mathrm{C}$ virus (HCV) infection can cause liver inflammation and cirrhosis, and is a significant public health problem as it affects 3 million people in the United States and 170 million people worldwide [1] with significant mortality. The renal manifestations of HCV infection are primarily a result of glomerular immune complex or cryoglobulin deposition, although viral cytopathic effects and autoimmune phenomenon due to viremia also play roles [2]. Activation of Toll-like receptors (TLR) have been implicated in immune complex and viral infection-mediated glomerulonephritis (GN), specifically TLR3 in HCV infection [2]. Of the glomerular manifestations of HCV infection, the most common pathological finding is membranoproliferative GN (MPGN), which is characterized by "tram tracking" or double contours of the glomerular basement membrane [2], most commonly in the context of cryoglobulinemic GN, specifically type II (mixed) cryoglobulinemia. Cryoglobulins are proteins (primarily immunoglobulins) that become insoluble and precipitate at temperatures colder than physiologic body temperature in vitro [2]. Immunofluorescence studies demonstrate glomerular immune complex deposits in mesangial areas and/or capillary walls, and ultrastructural analysis, performed by electron microscopy, of the deposits will often reveal the characteristic tubular or annular substructure of cryoglobulins.

The typical clinical manifestations of cryoglobulinemia are proteinuria, hematuria, and hypocomplementemia, with progressive renal function decline. Dermatologic manifestations are also common, in the form of purpura due to small vessel cryoglobulin deposition. Cryoglobulinemic vasculitis can uncommonly present clinically as a rapidly progressive GN (RPGN). Pathologic findings in these cases can also show an MPGN pattern of glomerular injury, but with the addition of cellular crescent formation and necrotizing features. It is important to note, however, that the presence of an MPGN pattern can be independent of any crescentic or necrotizing features, although they can provide an etiological clue to the more severe clinical presentation in HCV-infected patients. A smaller subset of HCV-infected 


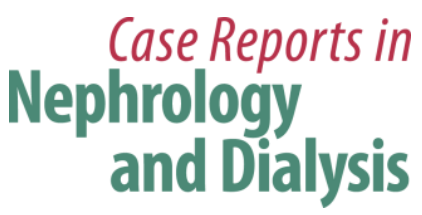

Case Rep Nephrol Dial 2018;8:161-170

patients have been shown to have anti-neutrophil cytoplasmic antibodies (ANCA) antibodies that are jointly present with positive cryoglobulin testing [3, 4]. Lamprecht et al. [5] found that $90 \%$ of these patients with HCV and mixed cryoglobulinemia displayed cryoglobulinemic vasculitis with an MPGN pattern. A smaller proportion of these patients displayed a crescentic GN pattern [5]. The targets of the ANCA antibodies are PR3 and cathepsin G in these chronically infected patients [6]. In comparison with hepatitis B infection, which is more commonly associated with large vessel disease (polyarteritis nodosa, PAN), HCV infection is predominantly associated with small vessel vasculitis (microsocopic polyangitis, MPA) [4, 7-10]. Although both PAN and MPA are p-ANCA-associated processes, they are distinguished from each other by size of affected arteries [7].

ANCA autoantibodies, with or without vasculitis, have also been found reported in autoimmune thyroiditis and other diseases [11-13], where they are thought to be related to the chronic inflammatory process. However, the presence of ANCA in HCV infection does not always correlate with ANCA-associated vasculitis on renal biopsy $[14,15]$. This may be due to false positive autoimmune assays in HCV infection, which are present in a high number of infected patients [16]. Nevertheless, c-ANCA and p-ANCA autoantibodies do seem to have an etiologic link to chronic infections such as HCV infection, and have been associated with biopsy-proven ANCA-associated vasculitis [7, 17-19]. In HCV-infected patients, ANCA titers appear to be related to viremia, likely due to an errant immune response secondary to HCV infection [20]. In the evaluation of renal disease in HCV infection, it is important to consider ANCA vasculitis, as this can occur both independently or in the presence of cryoglobulins [21, 22]. We report a case of an HCV-infected patient with ANCA disease as the primary pathological manifestation, without histologic evidence of MPGN or cryoglobulinemic GN.

\section{Case Report}

The patient is a 78-year-old Caucasian female with a past medical history of asymptomatic hyponatremia, thrombocytopenia, thoracic aortic aneurysm, renal artery stenosis, and well-controlled hypertension who presented in April of 2017 with pneumonia and hyponatremia. Urinalysis further revealed marked, 3+ hematuria (>1,000 RBCs), 2+ proteinuria, and chronic kidney injury with an elevated creatinine of $87.54 \mu \mathrm{mol} / \mathrm{L}(0.99 \mathrm{mg} / \mathrm{dL})$, up from a baseline of $61.89 \mu \mathrm{mol} / \mathrm{L}(0.7 \mathrm{mg} / \mathrm{dL})$. She also displayed moderately severe hyponatremia at $128 \mathrm{mEq} / \mathrm{L}$ (mmol/L), which was due to decreased water clearance secondary to acute kidney injury (AKI); there was appropriate antidiuretic hormone secretion due to hypovolemia.

Due to the hyponatremia, the patient was instructed to discontinue thiazide diuretics, restrict fluids, ensure adequate sodium and protein intake, and avoid nonsteroidal anti-inflammatory drugs. An AKI workup was negative, and ultrasound did not show any obstructive lesions. Repeat labs showed stabilization of serum creatinine at $86.65 \mu \mathrm{mol} / \mathrm{L}(0.98 \mathrm{mg} / \mathrm{dL})$, but with no improvement in renal clearance. The unusual aspect of her presentation was an active urine sediment with gross hematuria and confirmation of $3 \mathrm{~g}$ of protein/g of creatinine found on urine protein-to-creatinine ratio.

A serological and urological workup was undertaken in this patient who hitherto had not been diagnosed with any chronic infections or rheumatologic disease. There was no history of rash, sinusitis, or hemoptysis indicative of granulomatosis with polyangitis, and there was no 


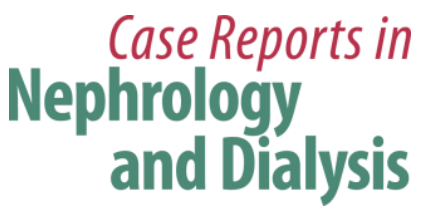

Case Rep Nephrol Dial 2018;8:161-170

flank pain or history of nephrolithiasis. Computed tomography (CT) urogram revealed a grossly normal urinary bladder and no evidence of radiopaque urinary calculi. CT further demonstrated the presence of left cortical and parapelvic renal cysts with no hydroureteronephrosis.

Upon serologic evaluation, the patient tested positive for hepatitis $C$ antibodies and demonstrated "marked" cryoglobulinemia. The patient was unaware of any history of hepatitis and was previously asymptomatic; however, she recalled having 12 units of blood transfusions for hemorrhage post-hysterectomy in 1976 at the age of 37, and transmission was attributed to that incident. Liver function tests were within normal limits with no evidence of cirrhosis and normal synthetic function with an albumin of $3.7 \mathrm{~g} / \mathrm{L}$, a prothrombin time of 11 $\mathrm{s}$, and an international normalized ratio of 1 . The patient was then referred to hepatology for workup and evaluation for hepatitis $\mathrm{C}$ curative therapy.

On additional evaluation, HCV RNA levels were 544,005 IU/mL. Furthermore, examination of the liver with Fibrospect II showed a fibrosis score of 24, indicative of mild disease. CT imaging of the liver was also unremarkable, with absence of nodularity, and the patient had unremarkable liver tests with normal platelet count and no history of jaundice, hepatic encephalopathy, gastrointestinal bleeding, ascities, or lower extremity edema. The patient was evaluated and deemed a good candidate for treatment and initiated sofosbuvir/velpatasvir for treatment of active hepatitis $\mathrm{C}$ infection for 12 weeks.

In addition to positive hepatitis $\mathrm{C}$ antibodies, serologic workup was positive for ANA, antidsDNA, and ANCA (p-ANCA $\geq 1: 1,280$, MPO Ab 24, PR3 Ab 134; c-ANCA 1:20), with normal levels of C3 and C4, and elevated levels of CH50 (>60). ESR and C-reactive protein were only slightly elevated at $35 \mathrm{~mm} / \mathrm{h}$ and $1 \mathrm{mg} /$ day, respectively. Given the positive ANCA findings, rheumatology was consulted to determine whether the findings represented cross-reactivity or ANCA disease. Though of uncertain relationship to the usual small vessel vasculitis seen in MPA, it was noted that the patient had a thoracic aortic aneurysm of $4.0 \mathrm{~cm}$ without rupture. The patient denied any rashes, joint pains, ulcers, Raynaud's phenomena, or any other rheumatologic history or known family history of autoimmune disease.

An ultrasound-guided renal biopsy was performed to determine the etiology of hematuria and proteinuria. At this time, due to the positive hepatitis $\mathrm{C}$ antibodies and cryoglobulinemia, it was though that the patient was likely to have a cryoglobulinemic vasculitis causing her AKI. However, the biopsy revealed necrotizing and crescentic ANCA GN with $25 \%$ active crescents. Immunofluorescence revealed low-grade mesangial IgM deposition without any associated significant glomerular proliferative features, suggestive of an incidental glomerular lesion. The lack of an MPGN pattern or any other proliferative pattern of glomerular injury was consistent with a primarily lesion of ANCA-associated crescentic GN. Furthermore, ultrastructural analysis did not demonstrate deposits in subendothelial locations, which are typically seen in cryoglobulinemic GN, nor were there any deposits with typical cryoglobulin substructure. Figure 1 demonstrates the pathologic findings in the renal biopsy.

With a diagnosis of a likely ANCA-associated GN, a treatment plan of Rituxan infusions dosed $0.375 \mathrm{~g} / \mathrm{m}^{2}$ for 4 weeks, according to the recommendations of the RAVE trial [23-25], with high-dose oral prednisone was initiated. Atovaquone $1,500 \mathrm{mg}$ daily was also prescribed for prophylaxis while on Rituxan infusions. Atovaquone was preferred over trimethoprim and sulfonamide to minimize the risk of hyperkalemia. 


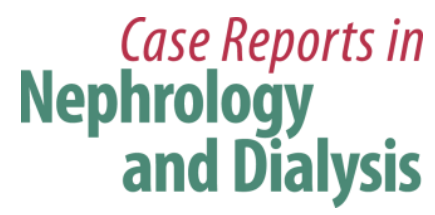

Case Rep Nephrol Dial 2018;8:161-170

Of note, physical examinations throughout the evaluation revealed auscultatory findings of bibasilar dry crackles. As p-ANCA disease can be associated with interstitial lung disease, this possibility was investigated [25]. The CT urogram, which included an incidental scan of the lower lung lobes, showed atelectasis and peribronchial thickening. Pulmonary function tests revealed mild restriction with total lung capacity at $72 \%$, and a dedicated chest CT scan confirmed mild pulmonary fibrosis with small airway disease.

After 7 weeks of treatment with sofosbuvir/velpatasvir, the patient's HCV RNA became undetectable. The patient currently has undergone 4 cycles of Rituxan without incident and was started on mycophenolate mofetil (MMF) for maintenance therapy. The proteinuria, which was first noted at $4.6 \mathrm{~g}$ of total protein per gram of creatinine upon quantification, was verified by 24 -hour protein collection, with nearly $4 \mathrm{~g}$ of protein per 24 -hour collection. After treatment, UPr/UCr decreased to $1.4 \mathrm{~g} / \mathrm{g}$ creatinine and 24-hour urine had markedly decreased to $<0.5 \mathrm{~g}$ per day of proteinuria in early August 2017, indicative of clinical remission (Fig. 2). As of December 2017, the patient remained clear of hepatitis C viremia, indicating a sustained clinical response despite immunosuppression. She is being maintained on low-dose prednisone and $1 \mathrm{~g}$ of MMF twice a day orally.

\section{Discussion}

The presentation of ANCA-associated disease in context of HCV infection is complex, and it is important to note that ANCA antibodies are not always pathogenic [14-16]. The perception that the presence of ANCA is always a result of false positive immunoassays [14] or due to a cross-reactivity with antibodies generated by HCV infection [16] is an oversimplification and can lead to either missing or misdiagnosing clinically relevant disease [7, 17-19]. ANCAassociated disease has pathological links to HCV infection with the finding of circulating antiPR3 ANCA autoantibodies [6]. PAN and MPA have been reported with hepatitis B virus infection and HCV infection, respectively. Thus, pathogenic ANCA antibodies can be generated by chronic viral infections including HCV [26].

The precise mechanism of ANCA formation in HCV infection is unknown, but it is likely secondary to acute-phase reactants due to prolonged exposure to viral antigens that are not often present in a healthy individual. These inflammatory proteins become detectable in serum in much higher concentrations, likely as a result of chronic antigenenia and sustained immune response in what is often a decades-long infection with HCV. There are many other autoimmune markers that can be positive in HCV infection, but the evidence in case highlight the fact that ANCA positivity should be a concern, as it may suggest underlying glomerular and/or interstitial lung disease [27]. The formation of ANCA's may herald the development of clinically significant autoimmunity, with often negative prognostic implications [28].

While cryoglobulins are the etiologic agent in a majority of hepatitis $C$ patients with skin findings and glomerular disease, this case demonstrates that ANCA disease can coexist with the systemic, mixed (type II) cryoglobulinemia, in the absence of cryoglobulinemic GN [28] (Table 1). This table was adapted from Kamar and Hawkins [7], with additional information specific to cases with hepatitis $\mathrm{C}$, cryoglobulinemia, and ANCA-associated disease.

Rituxan is now being utilized more frequently for c-ANCA and p-ANCA disease, with favorable data in induction and maintenance of remission [23-25]. Rituxan therapy for the 


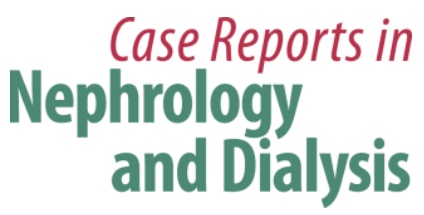

Case Rep Nephrol Dial 2018;8:161-170

DOI: $10.1159 / 000491629$

(c) 2018 The Author(s). Published by S. Karger AG, Basel www.karger.com/cnd

Hanna et al.: Case Report: Patient with Hepatitis C, p-ANCA, and Cryoglobulin Antibodies Presenting with Necrotizing Crescentic p-ANCA Glomerulonephritis

crescentic GN in this particular patient resulted in clinical remission. The decision to utilize MMF for maintenance therapy was due to the better tolerance than Imuran in elderly patients.

Of utmost clinical importance is to differentiate ANCA-associated crescentic GN from cryoglobulinemic GN with crescents, due to the profound treatment implications. While plasmapheresis is more often used to treat cryoglobulinemia, it is only used in cases of severe renal failure requiring hemodialysis and/or pulmonary hemorrhage in ANCA disease [29, 30]. Given these differences, we recommend that HCV-infected patients with positive ANCA serologies should be thoroughly examined for other possible systemic manifestations, and that they undergo renal biopsy in order to confirm the presence of ANCA-associated GN, with or without coexisting cryoglobulinemic vasculitis.

\section{Statement of Ethics}

This article does not contain any studies with human participants or animals performed by any of the authors.

\section{Disclosure Statement}

The authors have no conflicts of interest to declare.

\section{References}

1 Klevens RM, Hu DJ, Jiles R, Holmberg SD. Evolving epidemiology of hepatitis C virus in the United States. Clin Infect Dis. 2012 Jul;55 Suppl 1:S3-9.

2 Perico N, Cattaneo D, Bikbov B, Remuzzi G. Hepatitis C infection and chronic renal diseases. Clin J Am Soc Nephrol. 2009 Jan;4(1):207-20.

3 Asai O, Nakatani K, Yoshimoto S, Akai Y, Nishino T, Iwano M et al. [A case of MPO-ANCA-related microscopic polyangiitis with mixed cryoglobulinemia]. Nihon Jinzo Gakkai Shi. 2006;48(4):377-84.

4 Igaki N, Nakaji M, Moriguchi R, Akiyama H, Tamada F, Goto T. [A case of hepatitis C virus-associated glomerulonephropathy presenting with MPO-ANCA-positive rapidly progressive glomerulonephritis]. Nihon Jinzo Gakkai Shi. 2000 May;42(4):353-8.

5 Lamprecht P, Gutzeit O, Csernok E, Gause A, Longombardo G, Zignego AL et al. Prevalence of ANCA in mixed cryoglobulinemia and chronic hepatitis C virus infection. Clin Exp Rheumatol. 2003 Nov-Dec;21(6 Suppl 32):S89-94.

6 Wu YY, Hsu TC, Chen TY, Liu TC, Liu GY, Lee YJ et al. Proteinase 3 and dihydrolipoamide dehydrogenase (E3) are major autoantigens in hepatitis C virus (HCV) infection. Clin Exp Immunol. 2002 May;128(2):347-52.

7 Kamar FB, Hawkins TL. Antineutrophil Cytoplasmic Antibody Induction due to Infection: A Patient with Infective Endocarditis and Chronic Hepatitis C. Can J Infect Dis Med Microbiol. 2016;2016:3585860.

8 Kallinowski B, Seipp S, Fatehi S, Sommerfeld U, Andrassy K, Stremmel W et al. Significance of hepatitis B, hepatitis C and GBV-C in ANCA-positive hemodialysis patients. Nephron. 1997;77(3):357-8.

9 Ohira H, Tojo J, Shinzawa J, Suzuki T, Miyata M, Nishimaki T et al. Antineutrophil cytoplasmic antibody in patients with antinuclear antibody-positive chronic hepatitis C. Fukushima J Med Sci. 1998 Dec;44(2):83-92.

10 Sharma A, Sharma K. Hepatotropic viral infection associated systemic vasculitides-hepatitis B virus associated polyarteritis nodosa and hepatitis $\mathrm{C}$ virus associated cryoglobulinemic vasculitis. J Clin Exp Hepatol. 2013 Sep;3(3):204-12.

11 Bonaci-Nikolic B, Andrejevic S, Pavlovic M, Dimcic Z, Ivanovic B, Nikolic M. Prolonged infections associated with antineutrophil cytoplasmic antibodies specific to proteinase 3 and myeloperoxidase: diagnostic and therapeutic challenge. Clin Rheumatol. 2010 Aug;29(8):893-904. 
12 Bonaci-Nikolic B, Nikolic MM, Andrejevic S, Zoric S, Bukilica M. Antineutrophil cytoplasmic antibody (ANCA)-associated autoimmune diseases induced by antithyroid drugs: comparison with idiopathic ANCA vasculitides. Arthritis Res Ther. 2005;7(5):R1072-81.

13 Tajima Y, Miyazaki Y, Sudoh K, Matumoto A. [Intracranial hypertrophic pachymeningitis with high perinuclear anti-neutrophil cytoplasmic antibody (p-ANCA) occurred in a patient on hemodialysis]. Rinsho Shinkeigaku. 2002 Mar;42(3):243-6.

14 Cojocaru M, Cojocaru IM, Iacob SA. Prevalence of anti-neutrophil cytoplasmic antibodies in patients with chronic hepatitis $C$ infection associated mixed cryoglobulinemia. Rom J Intern Med. 2006;44(4):427-31.

15 Lamprecht P, Schmitt WH, Gross WL. Mixed cryoglobulinaemia, glomerulonephritis, and ANCA: essential cryoglobulinaemic vasculitis or ANCA-associated vasculitis? Nephrol Dial Transplant. 1998 Jan;13(1):21321.

16 Agarwal N, Handa R, Acharya SK, Wali JP, Dinda AK, Aggarwal P. A study of autoimmune markers in hepatitis C infection. Indian J Med Res. 2001 May;113:170-4.

17 Cojocaru IM, Cojocaru M, Burcin C. Ischemic stroke accompanied by anti-PR3 antibody-related cerebral vasculitis and hepatitis C virus infection. Rom J Intern Med. 2007;45(1):47-50.

18 Dalekos GN, Tsianos EV. Anti-neutrophil antibodies in chronic viral hepatitis. J Hepatol. 1994 Apr;20(4):561.

19 Zandman-Goddard G, Levy Y, Weiss P, Shoenfeld Y, Langevitz P. Transverse myelitis associated with chronic hepatitis C. Clin Exp Rheumatol. 2003 Jan-Feb;21(1):111-3.

20 Gatselis NK, Georgiadou SP, Koukoulis GK, Tassopoulos N, Zachou K, Liaskos C et al. Clinical significance of organ- and non-organ-specific autoantibodies on the response to anti-viral treatment of patients with chronic hepatitis C. Aliment Pharmacol Ther. 2006 Dec;24(11-12):1563-73.

21 Manna R, Todaro L, Latteri M, Gambassi G, Massi G, Grillo MR et al. Leucocytoclastic vasculitis associated with hepatitis C virus antibodies. Br J Rheumatol. 1997 Jan;36(1):124-5.

22 Papi M, Didona B, De Pità O, Gantcheva M, Chinni LM. Chronic hepatitis C virus infection, mixed cryoglobulinaemia, leukocytoclastic vasculitis and antineutrophil cytoplasmic antibodies. Lupus. 1997;6(9):737-8.

23 Geetha D, Specks U, Stone JH, Merkel PA, Seo P, Spiera R et al.; Rituximab for ANCA-Associated Vasculitis Immune Tolerance Network Research Group. Rituximab versus cyclophosphamide for ANCA-associated vasculitis with renal involvement. J Am Soc Nephrol. 2015 Apr;26(4):976-85.

24 Lamprecht P, Lerin-Lozano C, Merz H, Dennin RH, Gause A, Voswinkel J et al. Rituximab induces remission in refractory HCV associated cryoglobulinaemic vasculitis. Ann Rheum Dis. 2003 Dec;62(12):1230-3.

25 Stone JH, Merkel PA, Spiera R, Seo P, Langford CA, Hoffman GS et al.; RAVE-ITN Research Group. Rituximab versus cyclophosphamide for ANCA-associated vasculitis. N Engl J Med. 2010 Jul;363(3):221-32.

26 Konstantinov KN, Emil SN, Barry M, Kellie S, Tzamaloukas AH. Glomerular disease in patients with infectious processes developing antineutrophil cytoplasmic antibodies. ISRN Nephrol. 2013 Feb;2013:324315.

27 Katsumata Y, Kawaguchi Y, Yamanaka H. Interstitial Lung Disease with ANCA-associated Vasculitis. Clin Med Insights Circ Respir Pulm Med. 2015 Sep;9 Suppl 1:51-6.

28 Ragab G, Hussein MA. Vasculitic syndromes in hepatitis C virus: A review. J Adv Res. 2017 Mar;8(2):99-111.

29 Rockx MA, Clark WF. Plasma exchange for treating cryoglobulinemia: a descriptive analysis. Transfus Apheresis Sci. 2010 Jun;42(3):247-51.

30 Walters G. Role of therapeutic plasmapheresis in ANCA-associated vasculitis. Pediatr Nephrol. 2016 Feb;31(2):217-25. 


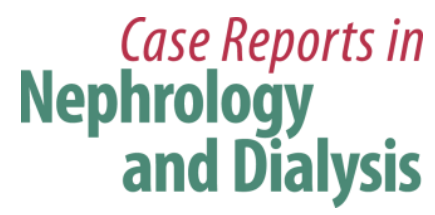

Case Rep Nephrol Dial 2018;8:161-170

(c) 2018 The Author(s). Published by S. Karger AG, Basel www.karger.com/cnd

Hanna et al: Case Report: Patient with Hepatitis C, p-ANCA, and Cryoglobulin Antibodies Presenting with Necrotizing Crescentic p-ANCA Glomerulonephritis
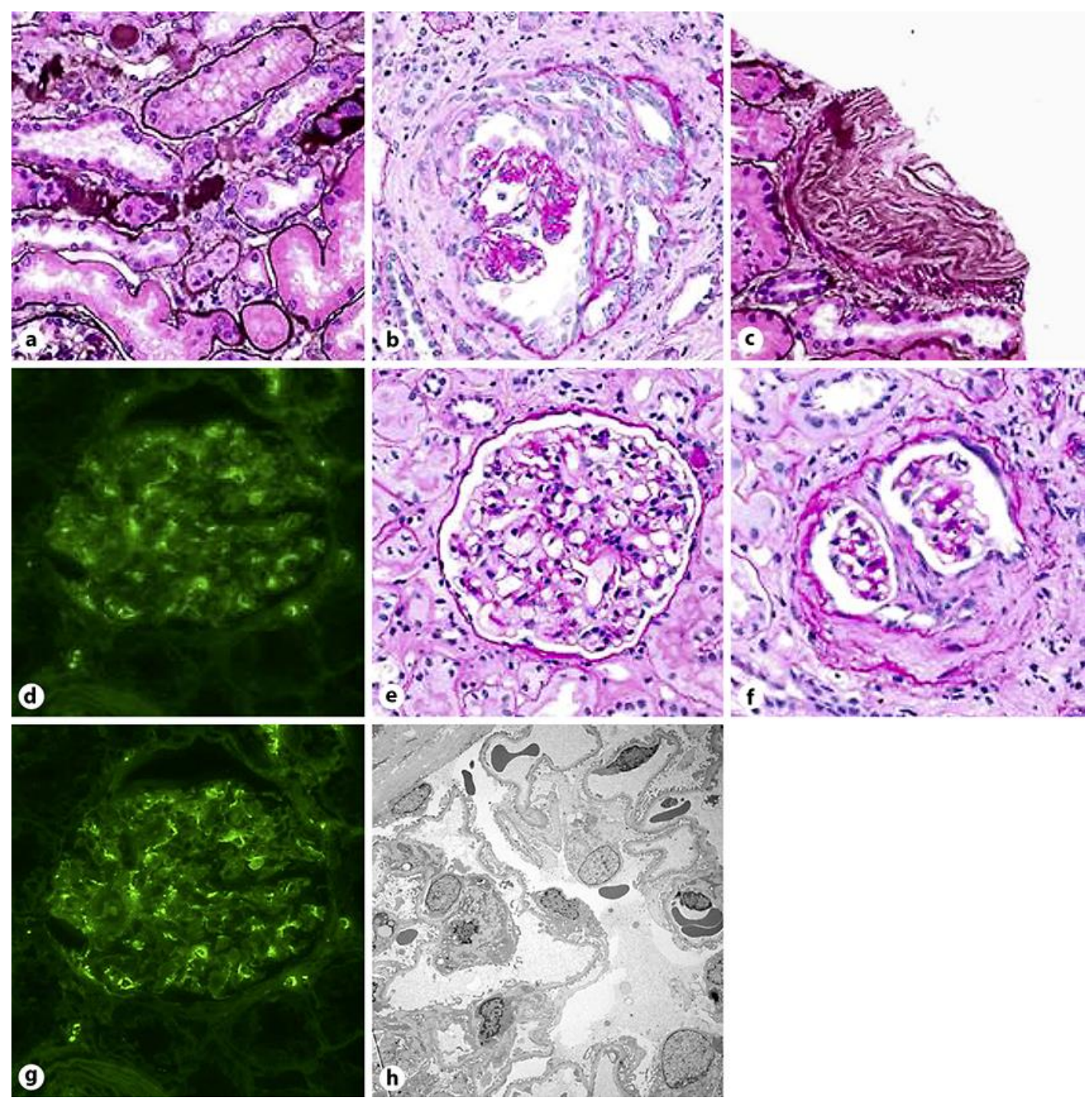

Fig. 1. Biopsy findings in patient showing predominant anti-neutrophil cytoplasmic antibody renal vasculitis and mild immune complex deposition possibly due to circulating cryoglobulin immune complexes. a Acute tubular necrosis, light microscopy. b Example of acute cellular crescent, light microscopy. c Intimal fibrosis, light microscopy. d Mesangial IgM deposition, immune fluorescence. e Mesangial proliferation, light microscopy. f Subacute fibro-cellular crescent, light microscopy. g Another view of immunofluorescence showing mild background IgM staining. $\mathbf{h}$ Electron micrograph showing no subendothelial electrondense deposits typical of classical cryoglobulinemia. 


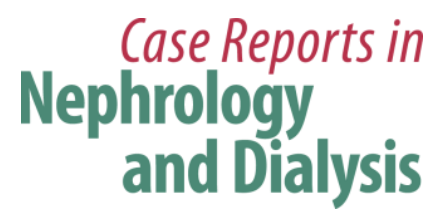

Case Rep Nephrol Dial 2018;8:161-170

(C) 2018 The Author(s). Published by S. Karger AG, Basel www.karger.com/cnd

Hanna et al.: Case Report: Patient with Hepatitis C, p-ANCA, and Cryoglobulin Antibodies Presenting with Necrotizing Crescentic p-ANCA Glomerulonephritis
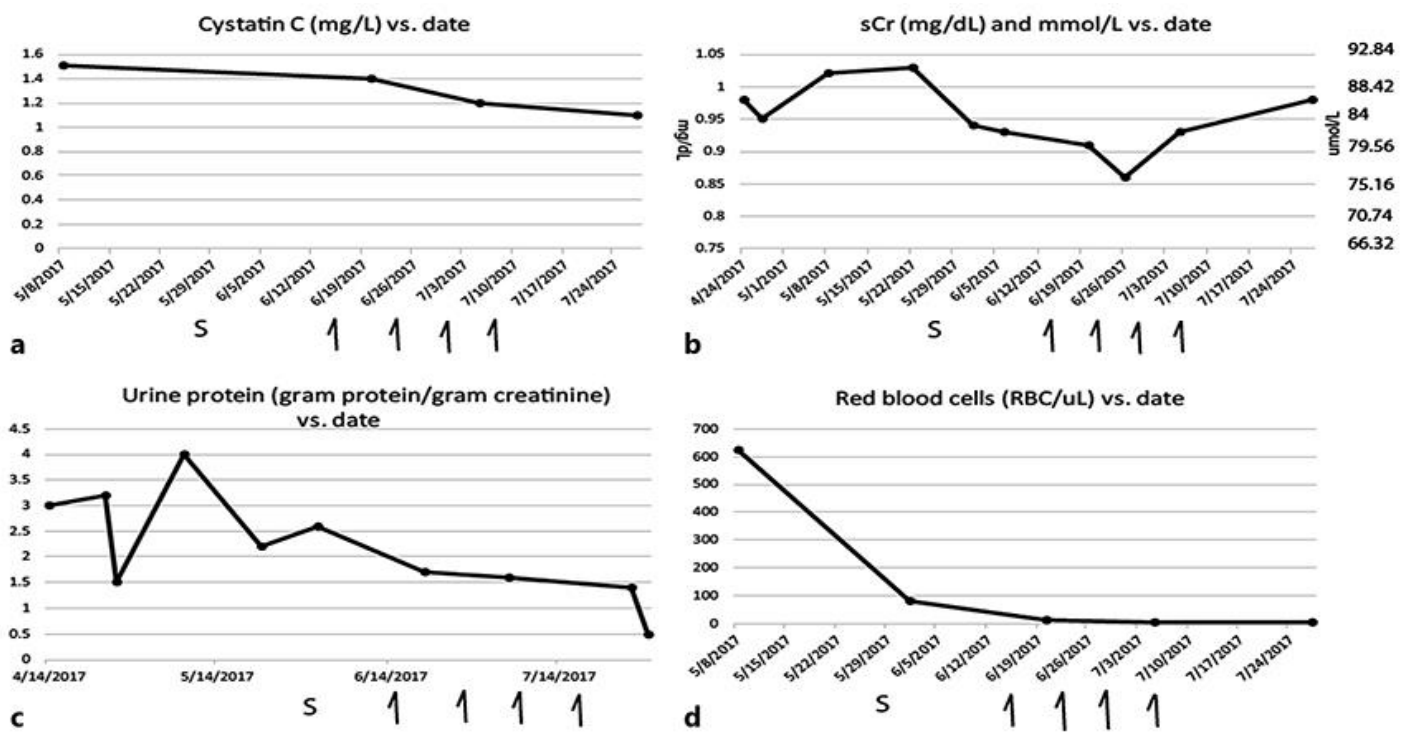

Fig. 2. Graphical representation of cystatin C (mg/L) versus date (a), serum creatinine ( $\mu$ mol/L) versus date (b), proteinuria (grams protein/gram creatinine) versus date (c), and hematuria urine red blood cells (RBC)/high power field vs. date (d). Arrows are Rituxan administration dates. S, steroids (40 mg of prednisone start date). 

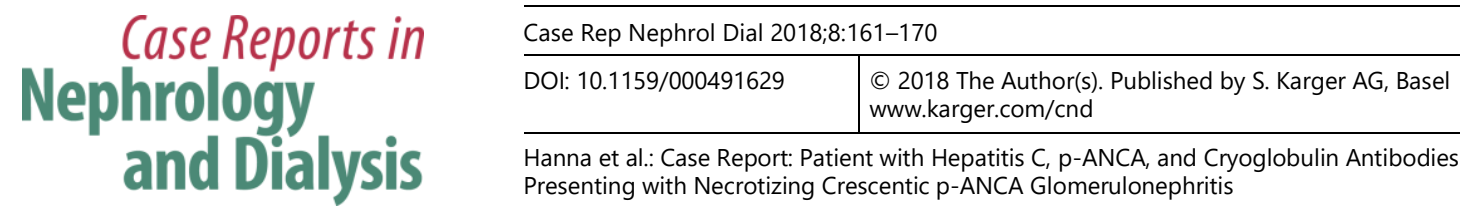

Table 1. Cases of hepatitis $C$ and ANCA disease, with emphasis on cases with ANCA and cryoglobulin marker presence

\begin{tabular}{|c|c|c|c|c|c|c|}
\hline \multicolumn{2}{|c|}{ Reference Type } & \multicolumn{2}{|c|}{$\begin{array}{l}\text { Renal bi-Cryo? } \\
\text { opsy? }\end{array}$} & \multirow{2}{*}{$\begin{array}{l}\mathrm{HCV}+/ \\
\text { ANCA+, } n \\
\\
1\end{array}$} & \multirow{2}{*}{$\begin{array}{l}\text { ANCA+/ } \\
\text { HCV+/ } \\
\text { Cryo+, } n\end{array}$} & \multirow{2}{*}{$\begin{array}{l}\text { if }+/+/+\mathrm{MC} \text { or } \\
\mathrm{AAV} ? \\
1 \mathrm{AAV}\end{array}$} \\
\hline 4 & MPO & yes & yes & & & \\
\hline 5 & PIP, CathG, c-ANCA, p-ANCA & yes & some & 11 & 11 & $8 \mathrm{MC}, 3 \mathrm{AAV}$ \\
\hline 6 & most PR3, some PR3 and MPO & no & no & 278 & 0 & $\mathrm{n} / \mathrm{a}$ \\
\hline 7 & PR3 & no & no & 3 & 0 & $\mathrm{n} / \mathrm{a}$ \\
\hline 9 & p-ANCA & no & no & 1 & 0 & $\mathrm{n} / \mathrm{a}$ \\
\hline 10 & PR3 & no & no & 21 & 0 & $\mathrm{n} / \mathrm{a}$ \\
\hline 11 & PR3, c-ANCA & yes & yes & 2 & 2 & $2 \mathrm{MC}$ \\
\hline 12 & p-ANCA & no & some & 5 & 0 & $\mathrm{n} / \mathrm{a}$ \\
\hline 13 & PR3 & no & no & 1 & 0 & $\mathrm{n} / \mathrm{a}$ \\
\hline 14 & 3 ANCA & no & no & 3 & 0 & $\mathrm{n} / \mathrm{a}$ \\
\hline 16 & both c-and p-ANCA & yes & no & 1 & 0 & $\mathrm{n} / \mathrm{a}$ \\
\hline 17 & 5 p-ANCA & no & no & 5 & 0 & $\mathrm{n} / \mathrm{a}$ \\
\hline 18 & 12 c-ANCA and p-ANCA & no & no & 12 & 0 & $\mathrm{n} / \mathrm{a}$ \\
\hline 20 & 65 c-ANCA, 4 p-ANCA & no & no & 69 & 0 & $\mathrm{n} / \mathrm{a}$ \\
\hline 22 & MPO & no & yes & 1 & 1 & $\mathrm{n} / \mathrm{a}$ \\
\hline \multicolumn{7}{|c|}{ current } \\
\hline case & PR3, MPO, p-ANCA>c-ANCA+ & yes & yes & 1 & 1 & $1 \mathrm{AAV}>\mathrm{MC}$ \\
\hline
\end{tabular}

+, positive; >, greater than; AAV, ANCA-associated vasculitis; ANCA, anti-neutrophil cytoplasmic antibody; c-ANCA, cytoplasmic anti-neutrophil cytoplasmic antibody; CathG, cathepsin G antibody; Cryo, cryoglobulins present; HCV, hepatitis $C$ virus; $\mathrm{MC}$, mixed cryoglobulinemia; MPO, anti-myeloperoxidase; p-ANCA, perinuclear anti-neutrophil cytoplasmic antibody; PIP, permeability-increasing protein antibody; PR3, proteinase 3 antibody. 